\title{
INFLUÊNCIA DA COMPOSIÇÃO DAS INCLUSÕES NO DESGASTE DE TAMPÃO DE DISTRIBUIDOR NO LINGOTAMENTO DE AÇOS ACALMADOS AO SILÍCIO- MANGANÊS *
}

\author{
Carlos Berlini Filho ${ }^{1}$ \\ Jorge Adam Cleto Cohn² \\ Maurício Covcevich Bagatini ${ }^{3}$
}

\section{Resumo}

As inclusões exercem um papel fundamental na lingotabilidade dos aços produzidos em lingotamento contínuo. E conhecido na literatura o efeito da composição das inclusões na formação de obstruções em válvulas submersas. Contudo, um problema também recorrente no ambiente industrial é o desgaste dos tampões e válvulas submersas do distribuidor, que impede o controle de fluxo de aço para os moldes. O presente trabalho visa avaliar a influência da composição das inclusões na taxa de desgaste de tampão. Foram avaliadas inclusões de aços acalmados ao Si-Mn em corridas que apresentaram diferentes valores de desgaste de tampão. A partir dos resultados obtidos foi possível concluir que a taxa de desgaste de tampão é consideravelmente dependente do teor de $\mathrm{MnO}$ das inclusões e que um maior teor de $\mathrm{Al}_{2} \mathrm{O}_{3}$ pode contribuir também para reduzir o desgaste.

Palavras-chave: Lingotamento; Desgaste; Tampão; Inclusões.

\section{INFLUENCE OF INCLUSIONS COMPOSITION ON THE TUNDISH STOPPER ROD WEAR DURING CASTING OF SI-MN KILLED STEELS}

\begin{abstract}
Inclusions play an important role in the castability of continuous casting steels. It is well established in the literature the effect of inclusions composition in submerged nozzles clogging. However, a problem as well common in industrial plants is stopper rod wear that suppresses steel flow control to the molds. The present work aims to evaluate the influence of inclusions composition on the stopper rod wear rate. It has been evaluated inclusions of Si-Mn killed steels in heats that have presented different wear rates. From the results it was possible to conclude that the wear rate is fairly dependent of the $\mathrm{MnO}$ amount in inclusions and higher $\mathrm{Al}_{2} \mathrm{O}_{3}$ values can contribute as well to reduce wear rate.
\end{abstract}

Keywords: Casting; Wear; Stopper; Inclusions.

1 Engenheiro Metalurgista, Mestrando do Programa de Pós-Graduação em Eng. de Minas, Metalúrgica e de Materiais, PPGEM, UFMG; Assessor Técnico da Área de Lingotamentos da Gerdau Usina Ouro Branco, Ouro Branco, MG, Brasil.

2 Engenheiro Metalurgista, Consultor Técnico da Área de Laminação de Planos da Gerdau Usina Ouro Branco, Ouro Branco, MG, Brasil.

3 Dr., Professor, nas Áreas de Siderurgia, Depto. de Eng. de Minas, Metalúrgica e de Materiais, PPGEM, UFMG, Belo Horizonte, MG, Brasil. 


\section{INTRODUÇÃO}

$\mathrm{Na}$ operação de distribuidores de lingotamento, a obstrução de válvulas submersas proveniente da deposição de inclusões sólidas é bem conhecida e tem sido assunto de extensiva investigação. Entretanto, pouco se tem publicado sobre o desgaste de refratários do distribuidor (tampões e válvulas submersas) devido a interações com inclusões líquidas. O objetivo deste trabalho está na análise de diferentes corridas de um mesmo tipo de aço que apresentaram comportamentos diversos concernentes ao desgaste dos refratários controladores de fluxo. Esta erosão, se demasiadamente alta, leva à interrupção do lingotamento pela impossibilidade de manutenção da variação do nível de aço no molde em valores aceitáveis.

A disposição do tampão e válvula submersa em um distribuidor de lingotamento pode ser vista na figura 1. Quando está totalmente assentado na entrada da válvula submersa, o tampão é capaz de bloquear totalmente a passagem de aço. Para se iniciar o lingotamento, sua posição é elevada gradativamente e permite o escoamento do aço líquido para o molde. Durante o lingotamento, a sua posição é controlada automaticamente para a manutenção de um nível de aço constante no molde.

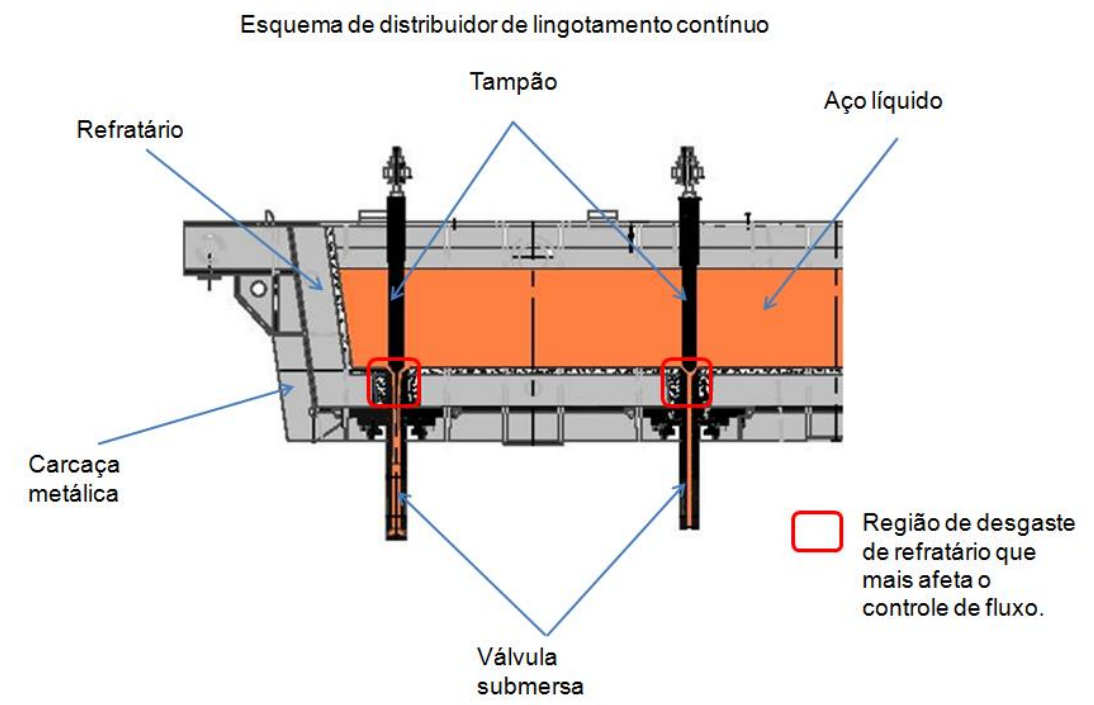

Figura 1: Esquema de um distribuidor com os tampões e válvulas submersas para controle de fluxo de aço. 0 desgaste na região dentro do retângulo afeta o controle de fluxo de aço para o molde.

Os tampões avaliados neste trabalho possuem na ponta refratário de $\mathrm{MgO}-\mathrm{C}$, isto é, grãos de $\mathrm{MgO}$ aglomerados por um ligante à base de carbono. São projetados para se encaixarem perfeitamente na parte superior da válvula submersa, conferindo estanqueidade total quando necessário e permitindo o controle de fluxo de aço sem variações excessivas. Quando ocorre o desgaste da ponta do tampão, as propriedades citadas são comprometidas. Na figura 2 (a), pode-se ver um tampão novo, antes de ser montado no distribuidor e na figura 2 (b), tampões retirados após o lingotamento e que apresentaram desgaste. A ponta destes últimos apresenta o efeito conhecido como penciling, que é a mudança da forma da ponta de um perfil arredondado para um perfil parecido com uma ponta de lápis. 


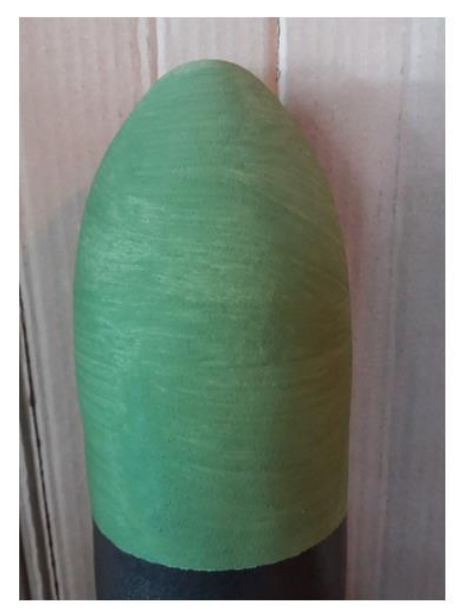

(a)
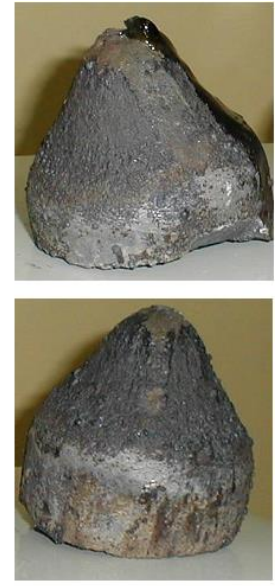

(b)

Figura 2: Aspecto da ponta de um tampão: (a) tampão novo e (b) tampões já utilizados.

A taxa de desgaste da ponta de um tampão pode ser avaliada pela mudança de sua posição em relação à válvula submersa ao longo do tempo. Se ocorrer o aumento da posição relativa entre eles, sugere que está ocorrendo obstrução da válvula submersa e o tampão é elevado a fim de compensar tal obstrução e manter o fluxo de aço constante. Ao contrário, se houver desgaste da ponta, sua posição relativa será abaixada com o mesmo intuito de não provocar variações de fluxo e manter uma determinada velocidade de lingotamento. A figura 3 mostra um gráfico da posição relativa do tampão e a variação de nível de aço no molde em relação ao tempo de lingotamento. Nota-se que, ao longo do tempo, há diferentes taxas de desgaste do tampão. Nos momentos finais do lingotamento, mostrado no retângulo de linhas tracejadas, há um acréscimo da variação de nível de aço no molde evidenciando que o tampão perdeu a capacidade de controle de fluxo e o lingotamento teve que ser interrompido.

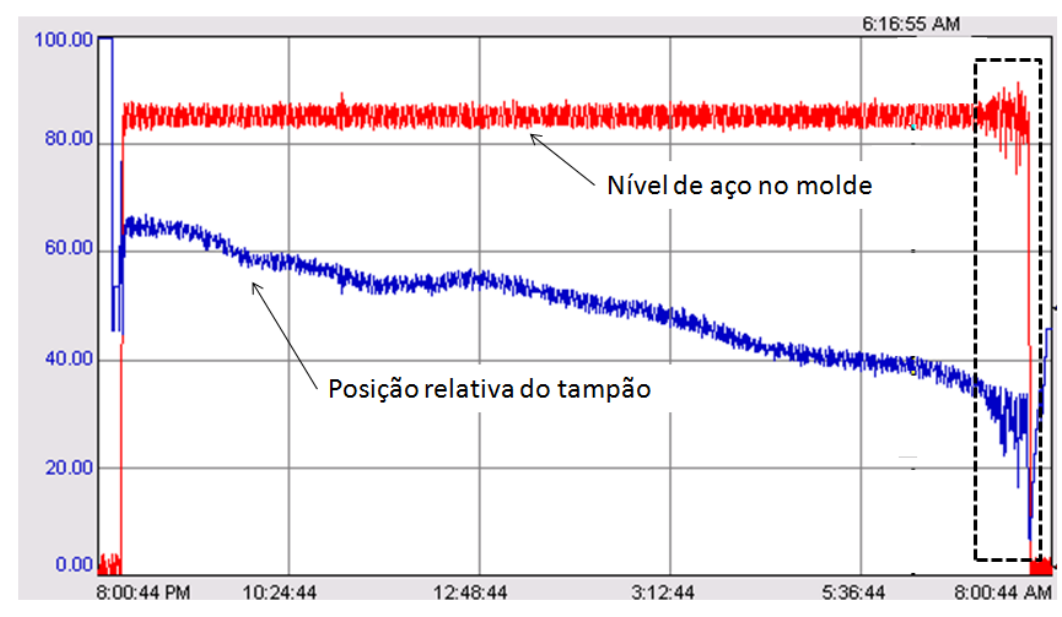

Figura 3: Posição relativa do tampão e variação de nível de aço no molde ao longo do lingotamento.

Normalmente, cada corrida lingotada no distribuidor confere ao tampão uma taxa de desgaste própria. Variações no processo de refino secundário e consequente variação na composição das inclusões podem ser a causa de diferentes taxas de desgaste para um mesmo tipo de aço, de acordo com XIE et al (2005). Os autores ainda citam que o fluxo de aço passa velozmente entre o tampão e a válvula 
submersa devido à pequena abertura entre eles. $\mathrm{O}$ contato entre o refratário do tampão e as inclusões do aço é assim intensificado devido à grande área superficial criada pela estreita passagem.

\subsection{Mecanismos de Desgaste de Refratários de MgO-C}

Refratários de MgO-C são comumente empregados em diferentes aplicações siderúrgicas, incluindo tampões de distribuidor e linha de escória de panelas de aço. São reconhecidos por apresentarem satisfatória resistência ao desgaste em uma ampla faixa de variação de composição de escória e aço.

Camelli \& Labadie (2006) citam que o principal mecanismo de desgaste de refratários de linha de escória de panela é a corrosão química e erosão mecânica devido à agitação do aço. Comentam ainda que foi possível observar a corrosão de grãos do refratário pela interação com $\mathrm{FeO}$ e $\mathrm{MnO}$ da escória, caracterizando uma reação de descarburação dos tijolos de $\mathrm{MgO}-\mathrm{C}$.

Xie et al (2005) apresentam o mecanismo de desgaste de refratário de MgO-C tendo como início a retirada da camada superficial de carbono através de reações envolvendo $\mathrm{FeO}$ e $\mathrm{MnO}$. Isto pode expor os grãos de $\mathrm{MgO}$ e causar a evolução de bolhas de $\mathrm{CO}$, conforme observado na figura 4. Posteriormente, os grãos de $\mathrm{MgO}$ expostos podem ser atacados e solubilizados nas inclusões ou, como perderam seu ligante, se desprenderem pela força de arraste do aço em contato. Uma nova camada de carbono ficará exposta e sofrerá a oxidação pelo $\mathrm{FeO}$ e $\mathrm{MnO}$, reiniciando o processo.

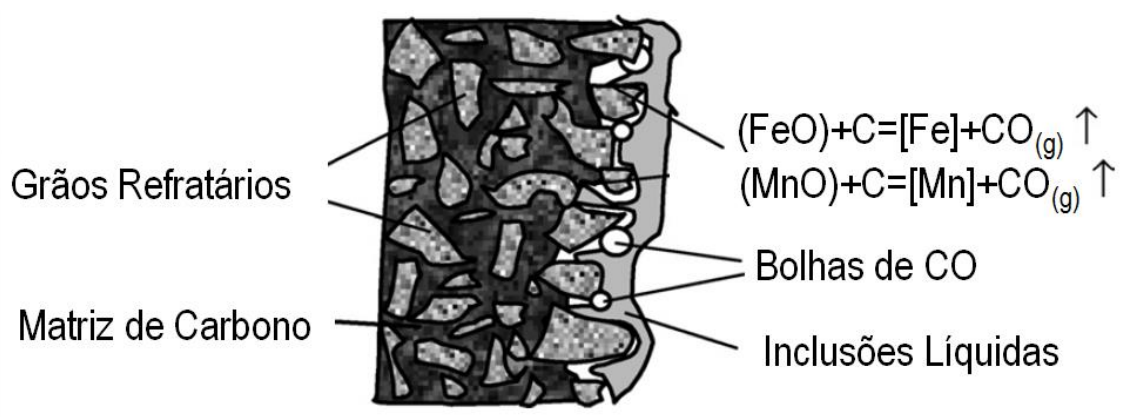

Figura 4: Ilustração esquemática da reação refratário-inclusão na face quente do refratário. Fonte: XIE et al (2005).

\section{MATERIAIS E MÉTODOS}

Aços ASTM-A572 foram produzidos em planta industrial através de lingotamento contínuo. Amostras de aço coletadas no distribuidor para análise de inclusões e valores de taxa de desgaste de tampão foram coletadas. A composição típica do aço ASTM-A572 pode ser vista na tabela 1, em percentuais em peso:

Tabela 1: Composição típica de aço ASTM-A572 produzido em planta industrial. Percentuais em peso.

\begin{tabular}{ccccccc}
\hline $\mathbf{C}$ & $\mathbf{M n}$ & $\mathbf{S i}$ & $\mathbf{P}$ & $\mathbf{S}$ & $\mathbf{N b}$ & $\mathbf{A l}$ \\
\hline 0,18 & 1,20 & 0,20 & $<0,030$ & $<0,040$ & 0,02 & $<0,010$
\end{tabular}

As taxas de desgaste de tampão foram calculadas subtraindo-se a posição do tampão no fim da corrida pela posição no início da corrida. Dividiu-se o valor pelo tempo decorrido entre os dois momentos e obteve-se a taxa de desgaste por corrida 
para cada veio. O valor médio entre veios representa o valor de desgaste utilizado para cada corrida deste estudo.

As amostras de aço coletadas durante o lingotamento e a composição química das inclusões foram analisadas utilizando MEV, fabricante FEI, modelo Quanta 400, com sonda EDS acoplada, da Oxford. Inclusões abaixo de $2 \mu \mathrm{m}$ de diâmetro equivalente não foram consideradas. A composição das inclusões foi normalizada para 0 sistema $\mathrm{MnO}-\mathrm{SiO}_{2}-\mathrm{Al}_{2} \mathrm{O}_{3}$.

\section{RESULTADOS E DISCUSSÃO}

Foram coletados dados de nove corridas e a composição das inclusões, normalizada para o sistema $\mathrm{MnO}-\mathrm{SiO}_{2}-\mathrm{Al}_{2} \mathrm{O}_{3}$, é mostrada na tabela 2. A maior taxa de desgaste de tampão média ao longo do lingotamento foi de $7,1 \mathrm{~mm} / \mathrm{h}$. Considera-se o valor de $2,0 \mathrm{~mm} / \mathrm{h}$ como desgaste máximo aceitável para que a vida do distribuidor não fique limitada. Em duas corridas obteve-se um desgaste nulo, o que mostra que há condições de processo favoráveis para que a vida do distribuidor seja maximizada.

Tabela 2: Dados de composição das inclusões e taxas de desgaste das corridas analisadas.

\begin{tabular}{|c|c|c|c|c|c|c|}
\hline \multirow[t]{2}{*}{ Corrida } & \multirow{2}{*}{$\begin{array}{c}\text { Taxa de } \\
\text { Desgaste de } \\
\text { Tampão Médio } \\
(\mathrm{mm} / \mathrm{h})\end{array}$} & \multicolumn{3}{|c|}{$\begin{array}{c}\text { Composição Média das Inclusões } \\
\text { Analisadas (\%) }\end{array}$} & \multirow{2}{*}{$\begin{array}{l}\text { Desvio } \\
\text { Padrão } \\
\text { do Teor } \\
\text { de MnO }\end{array}$} & \multirow[t]{2}{*}{$\begin{array}{l}\text { Relação } \\
{\mathrm{MnO} / \mathrm{SiO}_{2}}\end{array}$} \\
\hline & & $\mathrm{MnO}$ & $\mathrm{SiO}_{2}$ & $\mathrm{Al}_{2} \mathrm{O}_{3}$ & & \\
\hline 1 & 7,1 & 55,31 & 40,59 & 4,10 & 5,07 & 1,36 \\
\hline 2 & 5,4 & 49,05 & 42,58 & 8,37 & 8,53 & 1,15 \\
\hline 3 & 5,3 & 39,76 & 42,90 & 17,34 & 8,19 & 0,93 \\
\hline 4 & 4,9 & 40,41 & 35,31 & 24,28 & 7,75 & 1,14 \\
\hline 5 & 3,8 & 52,12 & 40,31 & 7,57 & 10,70 & 1,29 \\
\hline 6 & 2,1 & 40,13 & 49,92 & 9,95 & 10,98 & 0,80 \\
\hline 7 & 1,4 & 32,30 & 53,63 & 14,70 & 7,41 & 0,60 \\
\hline 8 & 0,0 & 30,97 & 54,50 & 14,53 & 8,68 & 0,57 \\
\hline 9 & 0,0 & 30,70 & 33,95 & 35,35 & 5,52 & 0,68 \\
\hline
\end{tabular}

Na figura 5 estão apresentados os dados de percentual médio do teor de MnO nas inclusões de cada corrida analisada comparados com a taxa de desgaste de tampão. Constata-se uma forte relação entre os teores de $\mathrm{MnO}$ e a taxa de desgaste, evidenciando a influência deste composto no fenômeno. 
\%MnO Inclusões $\mathrm{x}$ Desgaste Tampão

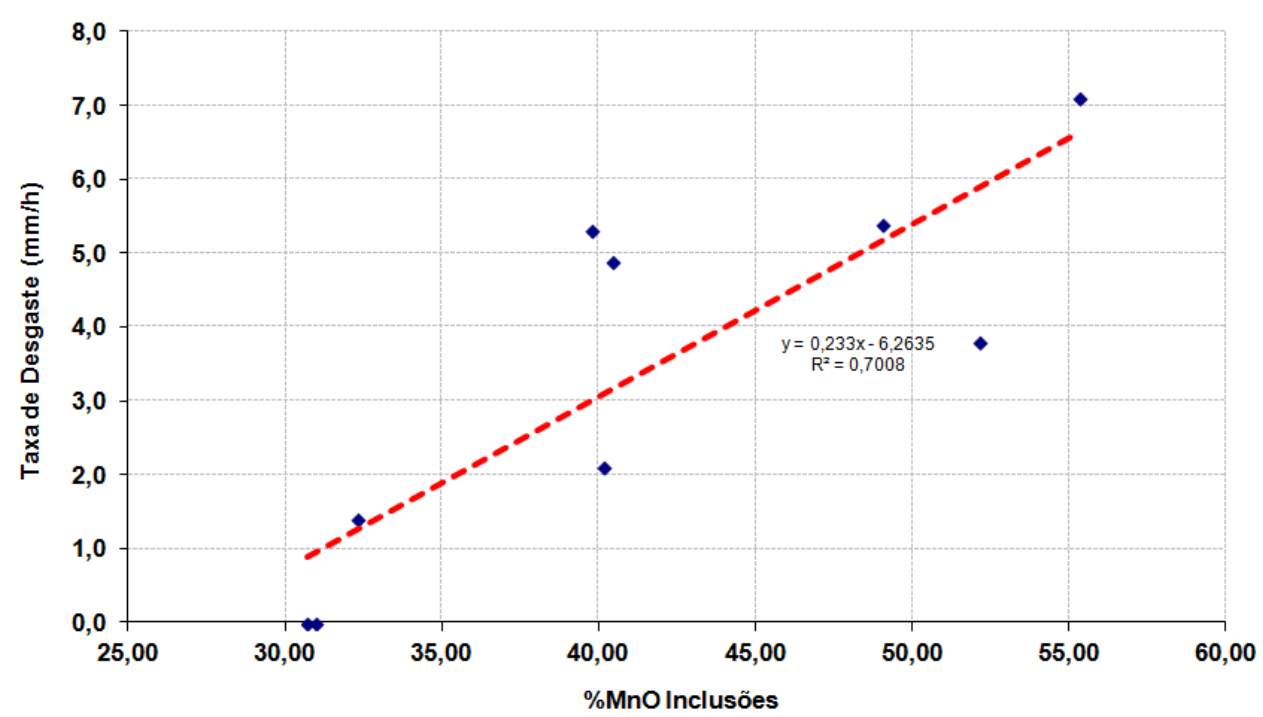

Figura 5: Taxa de desgaste de tampão em função do teor médio de MnO de cada corrida analisada.

Xie et al (2005) obtiveram resultados de desgaste de tampão de MgO-C também dependentes do teor de $\mathrm{MnO}$ da escória em contato com o refratário. Testaram dois tipos de escória, com diferentes teores de $\mathrm{MnO}$, vistos na tabela 3.

Tabela 3: Composição química (\% em peso) da escória utilizada nos testes de desgaste de tampão de MgO-C. Fonte: XIE et al (2005).

\begin{tabular}{ccccccc}
\hline Escória utilizada no teste & $\mathrm{Fe}_{2} \mathrm{O}_{3}$ & $\mathrm{CaO}$ & $\mathrm{SiO}_{2}$ & $\mathrm{Al}_{2} \mathrm{O}_{3}$ & $\mathrm{MnO}$ & $\mathrm{TiO}_{2}$ \\
\hline Escória B & - & 24,51 & 34,84 & 33,12 & 6,63 & 0,90 \\
Escória C & - & 0,05 & 37,71 & 28,53 & 33,17 & 0,54 \\
\hline
\end{tabular}

Os autores utilizaram a metodologia de avaliação de perda de massa do refratário para quantificar a taxa de desgaste. Descrevem detalhadamente a técnica de análise termogravimétrica em seu trabalho. $O$ refratário que ficou em contato com a escória $\mathrm{B}$, com o teor de $\mathrm{MnO}$ de 6,63\%, apresentou uma perda de massa devido as reações de desgaste aproximadamente dezesseis vezes menor que o teste realizado com a escória $\mathrm{C}$, com teor de $\mathrm{MnO}$ de $33,17 \%$. Ambos os testes foram realizados na temperatura de $1570^{\circ} \mathrm{C}$ e os refratários ficaram em contato com as escórias por duas horas. Os autores detectaram gotas de manganês metálico aderidas ao refratário como o produto da reação de redução do $\mathrm{MnO}$ da escória pelo carbono do refratário. Foi identificado também um ataque aos grãos de $\mathrm{MgO}$, nas análises do teste com a escória $\mathrm{C}$. A figura 6 mostra as peças refratárias de $\mathrm{MgO}-\mathrm{C}$ utilizadas no teste. Visivelmente se observa o desgaste mais acentuado do refratário submetido ao ataque da escória $\mathrm{C}$, rica em $\mathrm{MnO}$. 


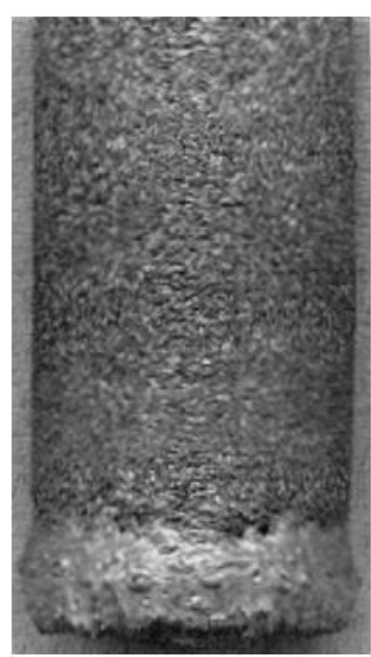

(a)

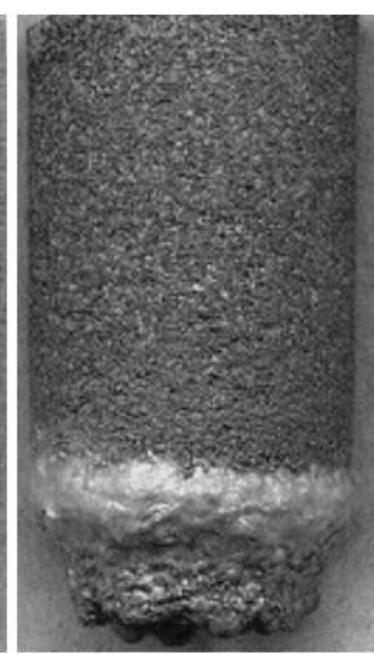

(b)

Figura 6: Amostras de refratário após o teste de atque pela escória B pobre em MnO (a), e escória C rica em $\mathrm{MnO}$ (b). Fonte: XIE et al (2005).

A composição média das inclusões de cada corrida estudada neste trabalho está disposta no ternário $\mathrm{MnO}-\mathrm{SiO}_{2}-\mathrm{Al}_{2} \mathrm{O}_{3}$ da figura 7 e representada de acordo com a taxa de desgaste observada.

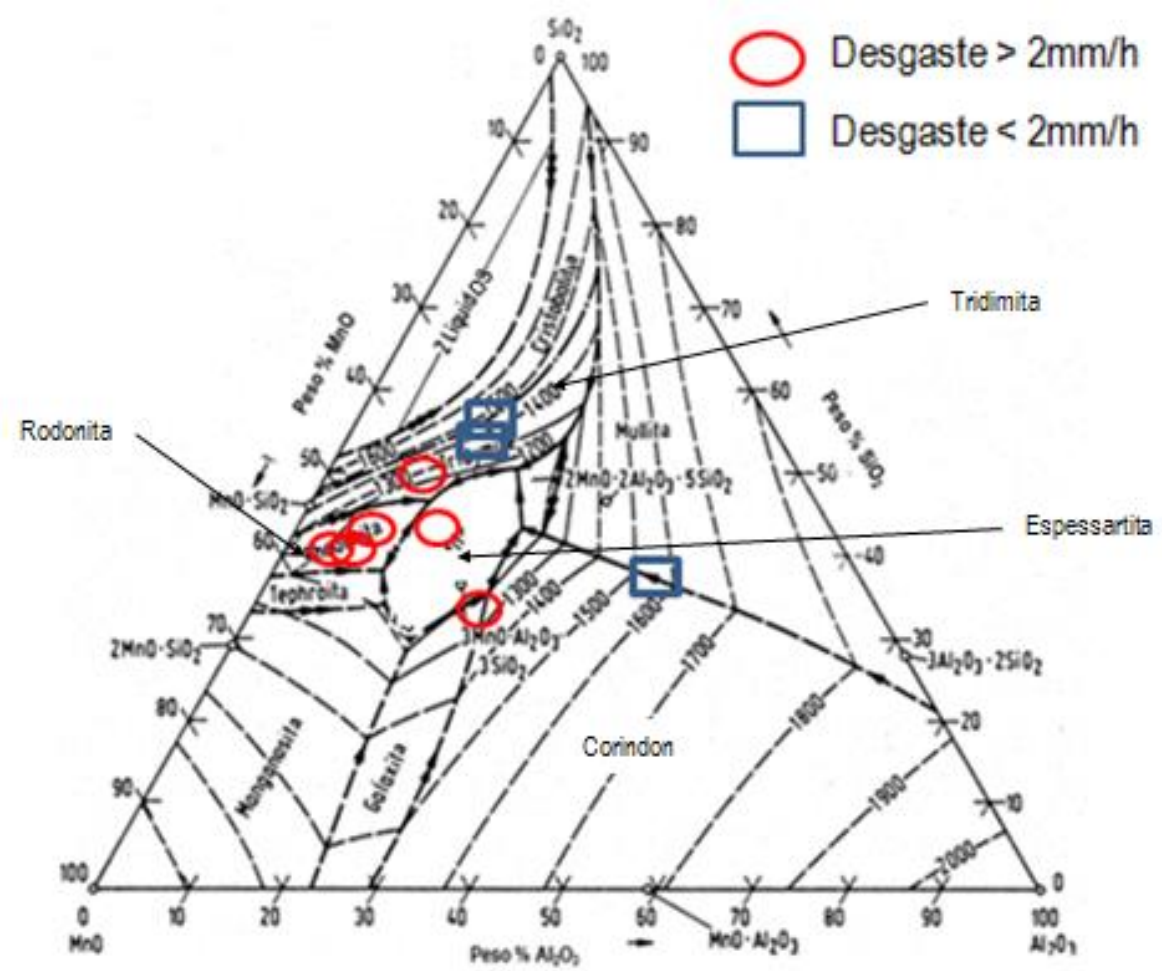

Figura 7: Ternário $\mathrm{MnO}-\mathrm{SiO}_{2}-\mathrm{Al}_{2} \mathrm{O}_{3}$ com a disposição da composição média das inclusões de cada corrida estudada com as respectivas taxas de desgaste apresentadas.

As inclusões que apresentaram sua composição média no interior do campo da isoterma de $1300^{\circ} \mathrm{C}$ possuem taxas de desgaste acima de $2 \mathrm{~mm} / \mathrm{h}$. A temperatura de lingotamento do aço apresentado neste estudo é da ordem de $1550^{\circ} \mathrm{C}$. Isto sugere que as inclusões que apresentaram maiores taxas de desgaste são 100\% líquidas à temperatura de lingotamento. Inclusões $100 \%$ líquidas e pouco viscosas podem molhar refratários com relativa facilidade e isto favorece a oxidação do carbono e 
solubilização dos grãos refratários de MgO pela escória. As corridas o 7 e 8 apresentaram taxas de desgaste abaixo de $2 \mathrm{~mm} / \mathrm{h}$. A composição de suas inclusões se encontram um pouco acima da isoterma de $1300^{\circ} \mathrm{C}$ e também são líquidas à temperatura de lingotamento do aço, contudo possuem teores de $\mathrm{MnO}$ abaixo de $40 \%$.

A corrida no 9 apresentou o maior teor de $\mathrm{Al}_{2} \mathrm{O}_{3}$ e o menor teor de $\mathrm{MnO}$ entre as corridas analisadas. A fim de comparação, a composição de cada inclusão analisada nas corridas no 3 e 9, que obtiveram desgastes de $5,3 \mathrm{~mm} / \mathrm{h}$ e zero, respectivamente, são mostradas na figura 8. $\mathrm{O}$ aumento do teor de $\mathrm{Al}_{2} \mathrm{O}_{3}$ para valores em torno de $35 \%$ contribuiu para a redução do teor de $\mathrm{MnO}$ e consequentemente a taxa de desgaste.

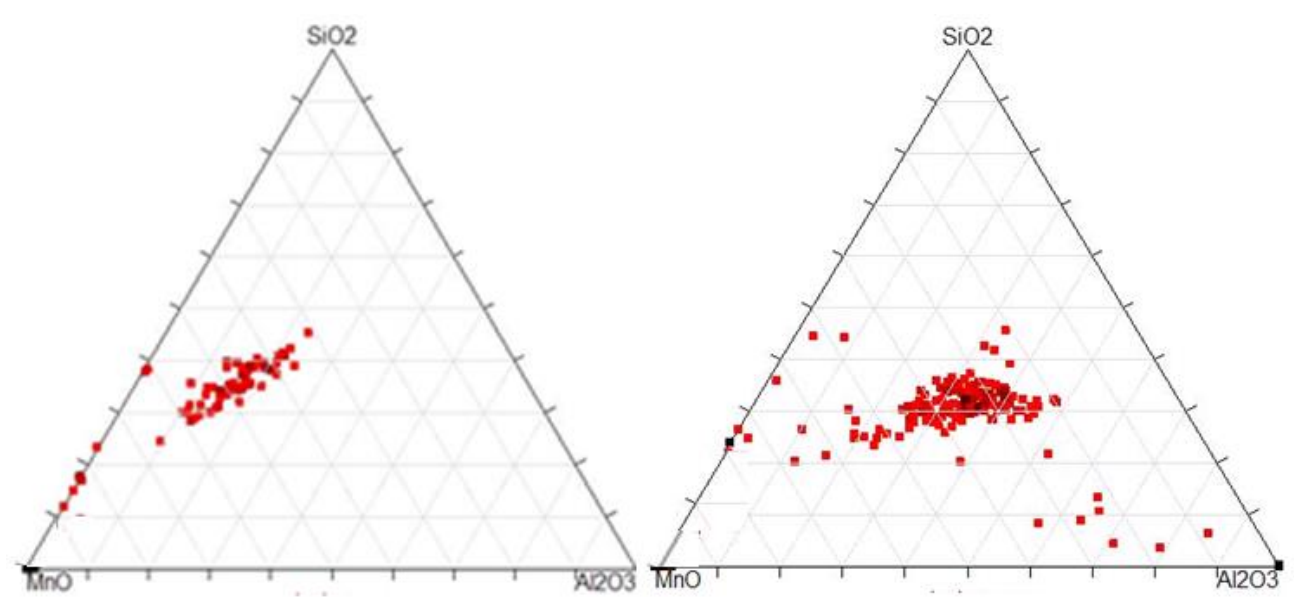

Figura 8: Composição das inclusões das corridas 3 e 8 dispostas no ternário $\mathrm{MnO}-\mathrm{SiO}_{2}-\mathrm{Al}_{2} \mathrm{O}_{3}$.

De acordo com os estudos de KANG et al (2004), a $\mathrm{Al}_{2} \mathrm{O}_{3}$ atua como fundente à medida que seu teor aumenta nas inclusões compostas de $\mathrm{MnO}_{\text {e }} \mathrm{SiO}_{2}$. A partir de certo teor, a temperatura de fusão começa a aumentar e supera a temperatura de fusão na ausência de $\mathrm{Al}_{2} \mathrm{O}_{3}$. $\mathrm{Na}$ figura 9, para uma relação de composição de inclusão $\mathrm{MnO} / \mathrm{SiO}_{2}=1$, observa-se que o aumento do teor de $\mathrm{Al}_{2} \mathrm{O}_{3}$ até $11 \%$ reduz a temperatura de fusão de $1520^{\circ} \mathrm{C}$ para $1140^{\circ} \mathrm{C}$. A partir deste teor a temperatura de fusão aumenta e quando o teor de $\mathrm{Al}_{2} \mathrm{O}_{3}$ atinge $34 \%$, tem-se a temperatura de fusão de $1520^{\circ} \mathrm{C}$. Acima deste teor, qualquer aumento de provocará um aumento da temperatura de fusão em relação à temperatura de fusão $\mathrm{Al}_{2} \mathrm{O}_{3}$ na ausência de $\mathrm{Al}_{2} \mathrm{O}_{3}$. A redução da fluidez da inclusão pelo aumento da temperatura de fusão e como consequência a própria redução percentual de $\mathrm{MnO}$ parece contribuir para o decréscimo da taxa de desgaste. 


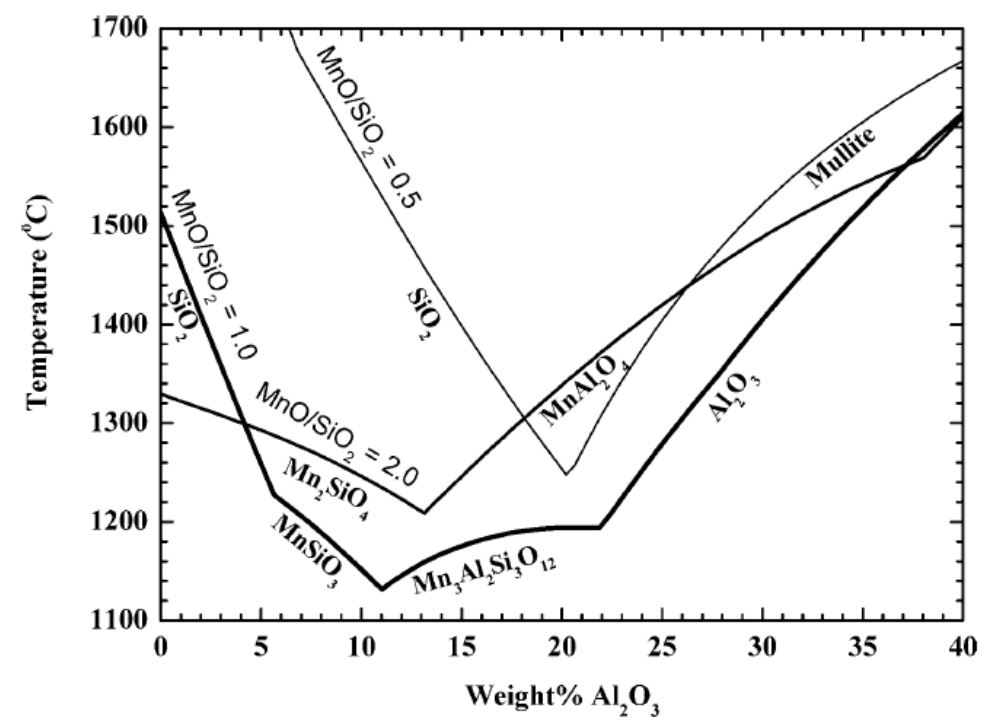

Figura 9: Temperatura liquidus calculada no sistema MnO-SiO2-Al2O3 como função da concentração de Al2O3. Relações $\mathrm{MnO} / \mathrm{SiO} 2$ de 0,5, 1,0 e 2,0 apresentadas. Fonte: KANG et al (2004).

\section{CONCLUSÃO}

A taxa de desgaste de tampão das corridas analisadas apresentaram boa correlação com o teor de $\mathrm{MnO}$ das inclusões presentes no aço, estando de acordo com os mecanismos da literatura apresentada. O mecanismo de desgaste está relacionado principalmente ao ataque da matriz de carbono, que serve como ligante para os grãos de $\mathrm{MgO}$ em um refratário $\mathrm{MgO}-\mathrm{C}$. As taxas são mais acentuadas quando as inclusões estão situadas em regiões de baixo ponto de fusão no diagrama $\mathrm{MnO}$ $\mathrm{SiO}_{2}-\mathrm{Al}_{2} \mathrm{O}_{3}$. As corridas que apresentaram um teor de $\mathrm{MnO}$ abaixo de $40 \%$ apresentaram desgaste de tampão nulo.

A presença de elevados teores de $\mathrm{Al}_{2} \mathrm{O}_{3}$ contribui para reduzir a taxa de desgaste de tampão, possivelmente pelo início de formação de fase sólida nas inclusões e consequente redução da penetração de escória no refratário. Uma maior adição de Al na corrida pode provocar a redução de $\mathrm{MnO}$ a $\mathrm{Mn}$ metálico dissolvido no banho e reduzir o percentual de $\mathrm{MnO}$ nas inclusões, com o consequente aumento do percentual de $\mathrm{Al}_{2} \mathrm{O}_{3}$. Portanto, um controle mais apurado das variáveis de refino secundário, como a adição de alumínio, contribui para a redução da taxa de desgaste de pontas de tampão refratário em aços acalmados ao Si-Mn.

\section{AGRADECIMENTOS}

Os autores agradecem o apoio da CAPES-PROEX, CNPq, FAPEMIG e Gerdau Usina Ouro Branco para a realização do presente trabalho.

\section{REFERÊNCIAS}

1 KANG, Y., LEE. H.; Inclusions Chemistry for Mn/Si Deoxidized Steels: Thermodynamic Predictions and Experimental Confirmations. ISIJ International, v.44, n.6, p1006-1015, 2004.

2 XIE, D., GARLICK, C., TRAN, T.; The Wear of Tundish Stopper Refractories by Inclusion Slags. ISIJ International, v.45, n.2, p. 175-182, 2005.

3 ARAROMI, O., THOMAS, B. G., CONZEMIUS, E.; Modeling of Clogging and Erosion of Nozzle Refractories in Steel Casting. Materials Science and Technology Conference, AIST/TMS, Pittsburgh, PA, Oct. 25-29, 2009.

4 CAMELLI, S., LABADIE, M.; Analysis of the Wear Mechanism of MgO-C Slag Line Bricks for Steel Ladles. Internationales Feuerfest-Kolloquium, p. 30-34, 2006. 